\title{
Sedimentation classification treatment effect of starting powders in slip casting on magneto-orientation of mordenite zeolite
}

\author{
Chika Matsunaga***, Tetsuo Uchikoshi**, Tohru S. Suzuki**, \\ Yoshio Sakka** and Motohide Matsuda* \\ *Graduate School of Science and Technology, Kumamoto University, 2-39-1 Kurokami Kumamoto, Kumamoto 860-8555 \\ Fax: 81-96-342-3726, e-mail: mm_2008@alpha.msre.kumamoto-u.ac.jp \\ **Nano Ceramics Center, National Institute for Materials Science, 1-2-1 Sengen Tsukuba, Ibaraki 305-0047
}

Fax: 81-29-859-2401, e-mail: UCHIKOSHI.Tetsuo@nims.go.jp

The magneto-orientation of mordenite zeolite during slip casting processes in a $12 \mathrm{~T}$ strong magnetic field was investigated using a commercial powder. When the as-received commercial powder was used, no orientation was observed. On the other hand, the mordenite zeolite was preferentially $b$-axis-oriented in the compacted disk prepared from powder classified by sedimention. Particle size distribution measurements revealed that agglomerated secondary particles larger than $2.8 \mu \mathrm{m}$ in size were removed by the sedimentation classification.

Key words: mordenite zeolite, orientation, agglomerated particles, magnetic alignment

\section{INTRODUCTION}

Zeolites are microporous crystalline solids with well-defined pore channels depending on their framework structures. Their channels (or pores) have molecular size dimensions; therefore, they are often termed "molecular sieves". Ceramic films of the zeolites are of great interest for practical applications such as molecular sieving separation devices, membrane reactors and chemical sensors.

Zeolite films are usually prepared by in situ crystallization ${ }^{1}$ or secondary growth under hydrothermal conditions $\mathrm{s}^{2-3}$. The secondary growth method has several advantages over the in situ synthesis. ${ }^{4}$ One of the advantages is that the influences of the support substrates can be eliminated by pre-coating a seed layer. This provides a much better reproducibility. Another advantage is the high flexibility to control the final film quality, because the microstructures of the subsequently-grown zeolite films are often derived from those of the precursors consisting of seed particles. ${ }^{5-9}$

Mordenite is one of the high silica zeolites and has an orthorhombic column framework with two-dimensional pores as shown in Fig. 1. ${ }^{10}$ The pore system consists of two kinds of different pore channels: elliptical main channels composed of a 12-membered ring $(0.67 \times 0.70 \mathrm{~nm})$ running along the $c$-axis, and the other one, composed of an 8-membered ring $(0.26 \times$ $0.57 \mathrm{~nm}$ ) running along the $b$-axis. ${ }^{11-12}$ If the selected axis of the mordenite is aligned normal to the substrate

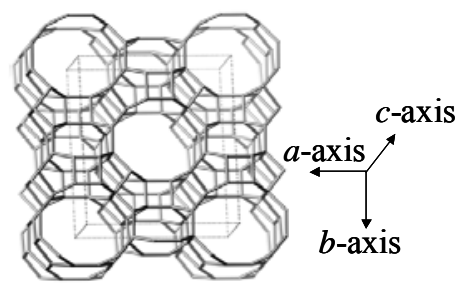

Fig. 1 Schematic of mordenite framework viewed along [001]. during the seeding process, it may lead to the preparation of an oriented mordenite film with highly ordered pore channels.

A magneto-scientific method has been one of the most useful techniques for the preparation of crystalline-oriented materials. ${ }^{13-17}$ Colloidal processing typified by slip casting in a strong magnetic field is one of the most effective processing techniques to prepare green compacts composed of oriented seed crystal particles. Such colloidal processes usually require stable suspensions to form highly ordered structures in the green compacts. In the present study, the compacted disks of mordenite zeolite have been prepared by the slip casting of commercial powder in a strong magnetic field. This manuscript reports the effects of the sedimentation classification treatments of the commercial powder on the magneto-orientation of the mordenite powder.

\section{EXPERIMENTAL PROCEDURE}

The mordenite powder used in this study was a highly siliceous $\mathrm{H}^{+}$-type mordenite zeolite (HSZ-640HOA, Tosoh Co., Ltd.; $\mathrm{SiO}_{2} / \mathrm{Al}_{2} \mathrm{O}_{3}=230$ ). The commercial mordenite powder was dispersed in distilled water by applying ultrasound for $10 \mathrm{~min}$. For sedimentation classification of the commercial mordenite powder, the suspension was placed for a fixed period without stirring and then the supernatant was used. For comparison, the suspension without any sedimentation classification was also used. The consolidation of the suspension was performed by slip casting in a $12 \mathrm{~T}$ strong magnetic field for which a superconducting magnet with a room temperature bore of $100 \mathrm{~mm}$ diameter (JMTD-12T100NC5, Japan Superconductor Tech., Inc.) was used. The direction of the magnetic field was parallel to the direction of the casting. The suspensions were kept in the magnetic field until completion of the slip casting. The resulting compacted disks had a thickness of $\sim 5 \mathrm{~mm}$. The 
obtained compacted disks were cut into segments in order to obtain structural information.

The particle size distribution of the powders before and after the sedimentation classification was measured using a laser light scattering particle size analyzer (NIKKISO Co., LTD., UPA-UT151). The zeta-potential of the mordenite was measured by a laser doppler method (Otsuka Electronics Co., Ltd., ELS-8000). The characterization of the powders before and after the sedimentation classification was performed using a scanning electron microscope (SEM) (JEOL, JSM-6500). The orientation of mordenite zeolite in the compacted disks was analyzed by X-ray diffraction (XRD) (JEOL, JDX-3500). The analyses were performed on the mutually orthogonal surfaces of the segments cut from the compacted disks.

\section{RESULTS AND DISCUSSION}

Fig. 2 shows the XRD pattern of the as-received mordenite powder. The as-received powder had a single mordenite zeolite phase and a good crystallinity.

Fig. 3 shows the zeta-potential of the mordenite in

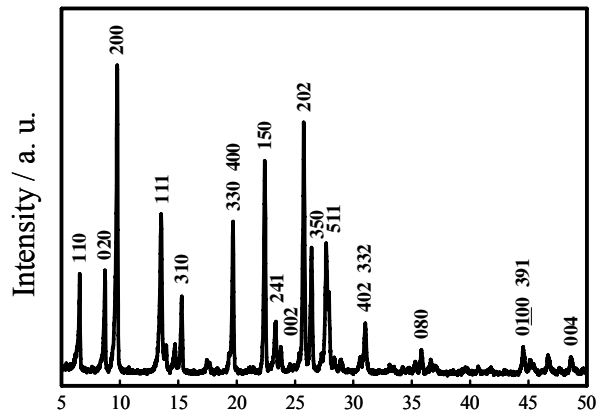

$2 \theta /$ degree

Fig. 2 XRD pattern of the as-received mordenite.

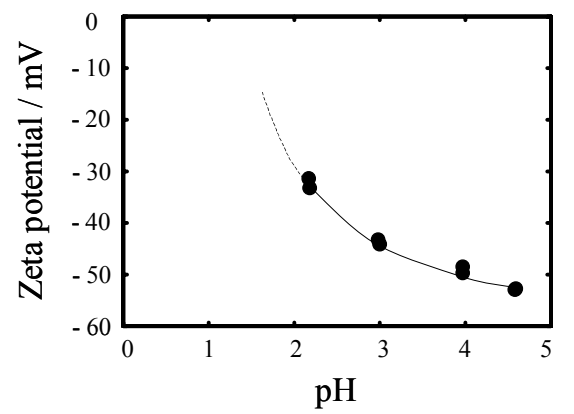

Fig. 3 Zeta potential of mordenite as a function of $\mathrm{pH}$.

water as a function of $\mathrm{pH}$. The as-dispersed mordenite aqueous suspension without $\mathrm{pH}$ adjustment had a $\mathrm{pH}$ of 4.6 and its zeta-potential was as high as $-53 \mathrm{mV}$.

From the zeta-potential data, a stable suspension was expected to be prepared without adding any acid/base or dispersants. However, in fact, it was difficult to disperse the as-received commercial powder by only the ultrasonic treatment. SEM observations revealed many agglomerated secondary particles with 5-50 $\mu \mathrm{m}$ diameters for the as-received powder (see Fig. 4 (a)). In order to de-agglomerate the large secondary particles in the commercial powder, the as-received powder was ball-milled using zirconia balls. The mordenite powder was, however, changed into an

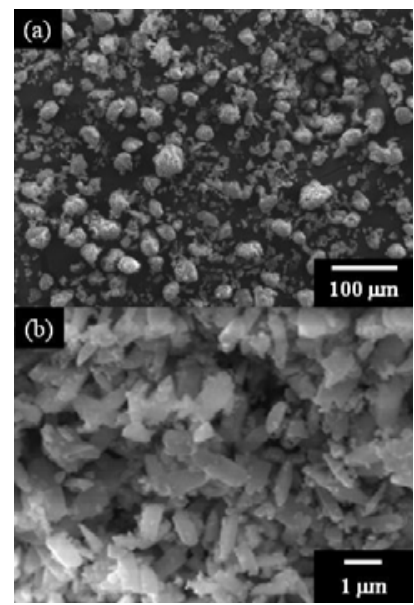

Fig. 4 SEM images of the mordenite powders before (a) and after (b) the sedimentation classification.

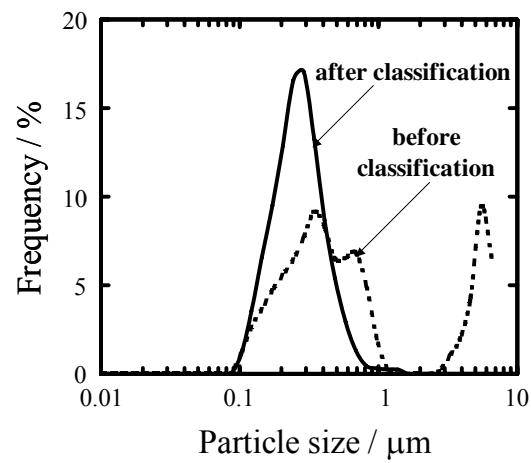

Fig. 5 Particle size distribution measured for the mordenite powders before and after the sedimentation classification.

amorphous phase after the ball milling. Therefore, the present study did not employ the ball milling process for de-agglomeration of the commercial powder. On the other hand, it seemed that the sedimentation classification effectively removed the agglomerated secondary particles from the as-received powder. The SEM observed no such agglomerated secondary particles in the powder after the sedimentation classification. Fig. 4 (b) is an SEM photograph of the mordenite powder after the sedimentation classification.

Fig. 5 shows the particle size distribution measured for the mordenite powder before and after the sedimentation classification. The particle size distribution of the as-received powder showed at least two peaks; a small powder with the particle size from 0.1 to $1.2 \mu \mathrm{m}$ and a large powder over $2.8 \mu \mathrm{m}$. (The upper limit of the detectable particle size of the particle size analyzer is $6.5 \mu \mathrm{m}$.) The large powder, which was probably agglomerated secondary particles, was completely removed after the sedimentation classification. The average particle size was $0.27 \mu \mathrm{m}$.

Fig. 6 shows the XRD patterns for the prepared compacted disk using the as-received powder containing the large agglomerated secondary particles before the sedimentation classification. The XRD patterns were taken of the top and side surfaces of the segment cut from the compacted disk. There was no significant difference in the two XRD patterns, and those XRD 


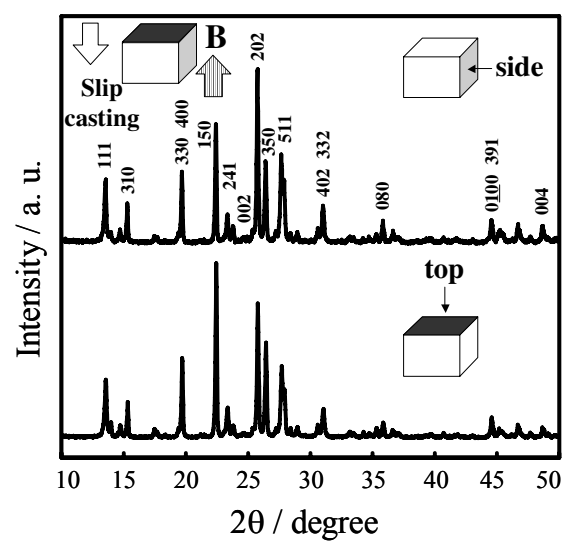

Fig. 6 XRD patterns of the top and side surfaces for the compacted disk prepared using the as-received powder before sedimentation classification. The compacted disk was prepared by slip casting in a static magnetic field which is parallel to the casting direction.

patterns were similar to those of the mordenite zeolite powder in Fig. 2. This indicates that the as-received mordenite zeolite powder was randomly packed during the slip casting process even in the $12 \mathrm{~T}$ strong magnetic field.

Fig. 7 shows the XRD patterns of the top and side surfaces for the compacted disk prepared using the classified powder of less than $1 \mu \mathrm{m}$ in size after the sedimentation. A difference was observed in the two XRD patterns. The peaks from the $0 k 0$ reflections disappeared in the XRD pattern of the side surface, while those peaks remained with a high intensity on the top surface. This comparison obviously indicated that the classified powder was preferentially $b$-axis-oriented in the prepared compacted disk. Our previous study ${ }^{18}$ has disclosed that the $b$-axis of the mordenite zeolite is an easy-magnetization axis. Based on these results, it is clear that the sedimentation classification has a good effect on the magneto-orientation of the mordenite zeolite in the slip cast.

\section{SUMMARY}

The magneto-orientation of the mordenite zeolite, the $b$-axis of which is an easy-magnetization axis, was investigated using the as-received and classified powders during the slip casting process. When the as-received powder was used, no orientation was observed. The $b$-axis-oriented disk of the mordenite zeolite was formed when the powder classified by sedimentation was used. The particle size distribution measurements revealed that the agglomerated secondary particles larger than $2.8 \mu \mathrm{m}$ in size were removed from the as-received powder by the sedimentation classification. Thus, it became apparent that the sedimentation classification treatment of the commercial powder was an important step to form highly ordered mordenite zeolite during the slip casting process in a strong magnetic field.

\section{(Acknowledgements)}

This work was financially supported, in part, by Grant-in-Aid for Scientific Research (C) (No. 2056062600) from Japan Society for the Promotion of Science (JSPS).

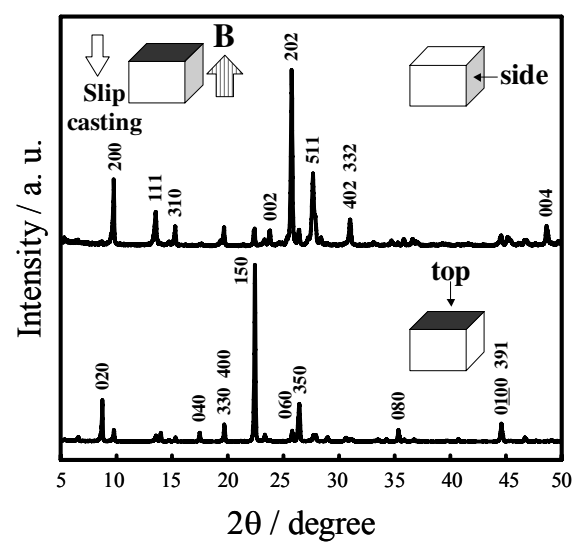

Fig. 7 XRD patterns of the top and side surfaces for the compacted disk prepared using the classified powder before sedimentation. The compacted disk was prepared by slip casting in a static magnetic field which is parallel to the casting direction.

\section{REFERENCES}

[1] M. Matsukata, M. Ogura, T. Osaki, P. Raja, H.P. Rao, M. Nomura, E. Kikuchi, Topics Catal. 9, 77-92 (1999).

[2] Z. Lai, G. Bonilla, I. Diaz, J.G. Nery, K. Sujaoti, M.A. Amat, E. Kokkoli, O. Terasaki, R.W. Thompson, M. Tsapatsis, D.G. Vlachos, Science 100, 456-60 (2003).

[3] J. Hedlund, F. Jareman, A.J. Bons, M. Anthonis, J. Membr. Sci. 222, 163-79 (2003) 163.

[4] J. Caro and M. Noack, Micropor. Mesopor. Mater., 115, 215-33 (2008)

[5] G. Xomeritakis, A. Gouzinis, S. Nair, T. Okubo, M. He, R.M. Overney, M. Tsapatsis, Chem. Eng. Sci. 54, 3521-31 (1999).

[6] S. Mintova, J. Hedlund, V. Valtchev, B. Schoeman, J. Sterte, J. Mater. Chem. 10, 2217-21(1998).

[7] T. Seike, M. Matsuda, M. Miyake, J. Mater. Chem. 12, 366-68 (2002).

[8] W. Shan, Y. Zhang, W. Yang, C. Ke, Z. Gao, Y. Ye, Y. Tang, Micropor. Mesopor. Mater. 69, 35-42 (2004).

[9] T. Kuzniatsova, Y. Kim, K. Shqau, P.K. Dutta, H. Verweij, Micropor. Mesopor. Mater. 103, 102-07 (2007).

[10] M. M. J. Treacy and J. B. Higgins, "Collection of simulated XRD powder patterns for zeoliotes (Fifth revised edition)", Elsevier Science, (2007) pp.284-85.

[11] W. M. Meier, Z. Kristallogr., 115, 439-450 (1961) [12] B. O. Hincapie, L. J. Garces, Q. Zhang, A. Sacco, and S. L. Micropor. Mesopor. Mater., 67, 19-26 (2004). [13]P. de Rango, M. Lees, P. Lejay, A. Sulpice, R. Tournier, M. Ingold, P. Germi and M. Pernet, Nature, 345, 770-72 (1991).

[14] T. S. Suzuki and Y. Sakka, Chem. Lett., 31, 1204-05 (2002).

[15]T. S. Suzuki, T. Uchikoshi and Y. Sakka, Sci. Tech. Adv. Mater., 7, 356-64 (2006).

[16] Y. Sakka and T. S. Suzuki, J. Ceram. Soc. Jpn., 113, 26-36 (2005)

[17]T. S. Suzuki, T. Uchikoshi and Y. Sakka, J. Eur. Ceram. Soc., 29, 2627-33 (2009).

[18]C. Matsunaga, T. Uchikoshi, T. S. Suzuki, Y. Sakka, and M. Matsuda, Chem. Lett. , 39, 347-49 (2010).

(Received January 25, 2010; Accepted July 1, 2010) 